\title{
Las células estrelladas del hígado: su importancia en condiciones normales y patológicas
}

\author{
M. Sarem ${ }^{\mathrm{a}}$, R. Znaidak ${ }^{\mathrm{a}}$, M. Macías ${ }^{\mathrm{b}}$ y R. Rey \\ ${ }^{a}$ Cátedra de Histología, Embriología, Biología Molecular y Genética. Facultad de Medicina. Instituto Universitario de Ciencias de la Salud. Fundación H.A. \\ Barceló. Buenos Aires. Argentina. \\ ${ }^{b}$ Cátedra de Anatomía Patológica y Fisiopatología. Facultad de Medicina. Instituto Universitario de Ciencias de la Salud. Fundación H.A. Barceló. Buenos \\ Aires. Argentina. \\ 'Cátedra de Medicina Interna. Facultad de Medicina. Instituto Universitario de Ciencias de la Salud. Fundación H.A. Barceló. Buenos Aires. Argentina.
}

\section{RESUMEN}

La fibrosis hepática es un proceso dinámico y regulado que se desencadena en respuesta a la lesión hepatocelular crónica provocada por diversas causas. La fuente principal de ese tejido fibroso son las células mesenquimales estrelladas del hígado (CEH), que se ubican en el espacio perisinusoidal de Disse entre los hepatocitos y las células endoteliales.

En condiciones fisiológicas, las CEH quiescentes desempeñan un papel fundamental al regular la homeostasis de los retinoides y la remodelación de la matriz extracelular (MEC) tanto por medio de su capacidad de sintetizar los componentes de ésta, como por su habilidad para producir diferentes metaloproteinasas degradantes de la MEC y sus inhibidores. Sin embargo, durante la fibrogénesis hepática, las CEH se activan diferenciándose en células parecidas a los miofibroblastos con capacidad proliferativa, fibrogénica y contráctil para desempeñar un papel primordial en la configuración de la fibrosis hepática y en el control del flujo sanguíneo del hígado.

En esta revisión se comentarán la morfología básica y las funciones de las CEH en condiciones normales y durante su activación en la fibrosis.

\section{HEPATIC STELLATE CELLS: IT'S ROLE IN NORMAL AND PATHOLOGICAL CONDITIONS}

Hepatic fibrosis is a dynamic and sophisticatedly regulated wound healing response to chronic hepatocellular injury. This fibrotic process results from the accumulation of extracellular matrix (ECM) including collagen, proteoglycan, and

\footnotetext{
Correspondencia: Dr. M. Sarem.

Cátedra de Histología, Embriología, Biología Molecular y Genética.

Facultad de Medicina. Instituto Universitario de Ciencias de la Salud. Fundación H.A. Barceló.

French 2464. Ciudad Autónoma de Buenos Aires. Argentina.

Correo electrónico: sarem@intramed.net
}

Recibido el 17-3-2005; aceptado para su publicación el 20-6-2005. adhesive glycoproteins which are principally produced by hepatic stellate cells (HSC), a mesenchymal cell type located between parenchymal cell plates and sinusoidal endothelial cells in the space of Disse.

In physiological conditions, quiescent HSCs play important roles in the regulation of retinoid homeostasis and ECM remodeling by producing ECM components as well as metalloproteases and its inhibitor.

However during hepatic fibrogenesis, HSCs are known to be activated or «transdifferentiated» to myofibroblast-like cells which play a pivotal role in ECM remodeling and hepatic blood flow regulation. Activation of HSC is now well established as the key process involved in the development of hepatic fibrosis.

Both basic morphology and functions of HSCs in normal conditions and its role in pathological fibrosis will be discussed in this review.

\section{INTRODUCCIÓN}

El desarrollo de la fibrosis hepática es un proceso dinámico que provoca la interrupción de las funciones hepáticas con disfunción del órgano. Generalmente, la fibrosis hepática se produce como una respuesta a la lesión hepatocelular crónica provocada por el abuso de bebidas alcohólicas, infecciones crónicas, enfermedades biliares y afecciones congénitas metabólicas, entre otras, y puede llegar a conducir a largo plazo al desarrollo de cirrosis y carcinoma hepatocelular.

Aunque el proceso de la fibrosis hepática aún no se conoce totalmente, durante los últimos años los continuos estudios acerca de su biología celular y molecular han permitido comprender muchos detalles relacionados con su fisiopatogenia. La identificación de las células estrelladas del hígado (también llamadas lipocitos, células almacenadoras de grasa o células de Ito) y su gran importancia en la fibrosis hepática no solamente han modificado el enfoque de las in- 
vestigaciones sobre la base patogénica de la fibrosis hepática, sino que también han abierto nuevas líneas de interesantes investigaciones sobre futuras estrategias terapéuticas capaces de frenar el proceso fibrogénico.

\section{CONCEPTOS GENERALES SOBRE LAS CÉLULAS ESTRELLADAS}

Fue Karl Kupffer quien en el año 1876 descubrió las células estrelladas del hígado (CEH) cuando intentaba buscar fibras nerviosas en el hígado utilizando la técnica de cloruro de oro ${ }^{1}$. Logró así identificar un grupo de células que presentaban prolongaciones que entraban en contacto con la pared sinusoidal y con los hepatocitos, a las que llamó «Sternzellen» (células estrelladas).

Hoy sabemos que las células estrelladas son células mesenquimales, perisinusoidales ubicadas a lo largo de los sinusoides en el espacio perisinusoidal de Disse, aunque también pueden observarse entre las células parenquimatosas $^{2-4}$. Clásicamente el espacio de Disse se define como la zona limitada por los hepatocitos y la pared sinusoidal formada por las células endoteliales sinusoidales ${ }^{4,5}$. Normalmente este espacio contiene fibras nerviosas y algunos componentes de la matriz extracelular (MEC) como, por ejemplo, fibras colágenas de tipos I y III y componentes de la membrana basal que, por lo general, no llegan a formar una membrana basal verdadera ${ }^{5-7}$.

En su estado quiescente las CEH constituyen el 5-8\% del número total de células hepáticas considerando las parenquimatosas (hepatocitos), las endoteliales (tanto sinusoidales como vasculares), las células de Kupffer (macrófagos), las células epiteliales de la vía biliar y las $\mathrm{CEH}^{8-10}$. $\mathrm{Su}$ citoplasma se caracteriza por presentar múltiples y prominentes «gotitas» de grasa de 1 a $2 \mu \mathrm{m}$ de diámetro $^{2,3,11}$. Estas gotitas de grasa representan el principal sitio de almacenamiento de vitamina A (retinol). Más del $90 \%$ de la vitamina A hepática (el $80 \%$ del total del organismo) se halla almacenado en las $\mathrm{CEH}$, mientras que el resto se encuentra en las células parenquimatosas ${ }^{12-14}$.

En las CEH, desde su pericarion nacen numerosas largas y finas prolongaciones citoplásmicas denominadas «procesos» o «prolongaciones primarias», que corren a lo largo de los sinusoides. De estas prolongaciones primarias surgen las prolongaciones secundarias, que entran en contacto directo con las células endoteliales ${ }^{15-17}$. Observaciones recientes revelan la presencia de «microespinas» que nacen de los procesos citoplásmicos y que interactúan con las células parenquimatosas delimitando un espacio entre éstas y las CEH donde se encuentran fibras colágenas y también fibras nerviosas. Estas observaciones pueden modificar el clásico concepto del espacio de Disse a otro definido como un espacio situado entre los hepatocitos, por un lado, y las CEH y el endotelio sinusoidal por el otro ${ }^{15}$.

En condiciones normales, las CEH cumplen varias funciones en el hígado como, por ejemplo, la ya mencionada función de almacenar la vitamina A, controlar la comunicación intercelular por medio de la liberación de varios mediadores intercelulares ${ }^{18-20}$ y remodelar gran parte de la poca MEC presente en un hígado normal por medio de: a) la producción de los componentes colágenos y no colágenos de la $\mathrm{MEC}^{20-22} ; b$ ) la síntesis de las llamadas metaloproteinasas de la MEC (MMP, del inglés matrix metalloproteinase), que son un grupo de enzimas capaces de catabolizar los componentes de la $\mathrm{MEC}^{23,24}$, y $c$ ) la síntesis de los inhibidores de las MMP o inhibidores tisulares de metaloproteinasas (TIMP, del inglés tissue inhibitor of metalloproteinase), que tienden a controlar la actividad catalítica de las MMP a fin de mantener las sustancias de la matriz intersticial en un concentración estable ${ }^{25,26}$. Estas últimas funciones de las CEH tienen como propósito básico controlar la homeostasis tisular y mantener una especie de equilibrio fisiológico entre la síntesis y la degradación de los componentes de la MEC.

\section{FISIOPATOGENIA DE LA FIBROGÉNESIS HEPÁTICA}

La fibrogénesis hepática se define como un complejo y dinámico proceso fisiopatológico caracterizado por el depósito de tejido fibroso en el hígado como consecuencia de un desequilibrio entre la producción y la degradación de los componentes de la MEC en respuesta a varias agresiones repetitivas o crónicas de intensidades suficientes para conducir a este proceso de cicatrización. Independientemente de la causa, existe una progresiva deposición de múltiples tipos de proteínas colágenas y no colágenas en el intersticio y en el espacio de Disse.

\section{Activación de las células estrelladas del hígado}

Tras la lesión crónica del tejido hepático resultante de cualquier etiología, tanto las CEH como las otras células productoras de la MEC presentes en el tracto portal sufren un proceso anormal que se denomina «activación». La activación de las CEH es un proceso patológico que se caracteriza por la pérdida de las típicas gotitas de grasa, el aumento del número y tamaño celulares y la transdiferenciación fenotípica a células proliferativas, fibrogénicas y contráctiles muy similares a los miofibroblastos. Tanto los estímulos patológicos como los mediadores intercelulares y los cambios de la MEC son factores de vital importancia para llevar a cabo dicha activación celular ${ }^{8,27,28}$. El inicio del proceso de la activación de las CEH se produce por:

1. El impacto de la lesión de las células parenquimatosas o las células del tracto biliar sobre la homeostasis tisular. 2. Los efectos de los estímulos citocínicos provenientes tanto de células inflamatorias como de células vecinas.

3. Las modificaciones en la composición de la MEC, que las CEH perciben por medio de los receptores de aquélla, integrinas que conectan componentes de la MEC al citosqueleto ${ }^{27-30}$. Todas estas alteraciones provocan en las CEH importantes cambios en la expresión genética que generan una serie de modificaciones fenotípicas que les permiten responder a los crecientes estímulos patológicos 
locales. Estas modificaciones fenotípicas en las CEH activadas se sostienen por medio de una compleja y sofisticada señalización intercelular autocrina y paracrina ${ }^{19,31,32}$. Aunque la lista de los mediadores intercelulares que intervienen en este proceso se actualiza continuamente, la siguiente clasificación en grupos nos permite ordenar los mediadores intercelulares de mayor importancia.

- Mediadores inductores de la proliferación y/o motilidad celulares: el factor de crecimiento derivado de las plaquetas, el factor de crecimiento básico de los fibroblastos y el factor de crecimiento insulinoide 1.

- Mediadores fibrogénicos: los 2 más importantes son el factor transformador del crecimiento tipo $\beta 1$ (TGF- $\beta 1$ ) y la interleucina 6.

- Mediadores inductores de la contracción de las CEH, tales como la endotelina-1, la trombina, la angiotensina II y la vasopresina.

- Mediadores con actividad antiinflamatoria y antifibrogénica: la interleucina-10 y el interferón gamma.

También es importante recordar el papel del estrés oxidativo en la activación de las CEH. Varios estudios experimentales señalan que las especies reactivas de oxígeno, como el peróxido de hidrógeno $\left(\mathrm{H}_{2} \mathrm{O}_{2}\right)$ y los radicales libres, están implicadas en el desarrollo y la progresión de diversas enfermedades como la esclerosis múltiple, el sida, la enfermedad de Alzheimer y la lesión hepática crónica, entre otros. Estos productos metabólicos son tóxicos para el organismo y conducen a alteraciones del metabolismo celular, inhibición del crecimiento y finalmente la muerte celular. Por fortuna el organismo dispone de un grupo de sistemas de enzimas antioxidantes para contrarrestar los efectos tóxicos de las especies reactivas de oxígeno ${ }^{24}$.

Según otros autores ${ }^{24,33}$, el proceso de activación de las CEH puede dividirse en 2 etapas, una de iniciación y otra de perpetuación. La iniciación (también llamada etapa preinflamatoria) corresponde a los primeros acontecimientos del proceso y comprende los cambios rápidos de la expresión genética y del fenotipo que permiten a las CEH responder a los estímulos locales y citocínicos; es el resultado de los estímulos paracrinos provenientes de las células vecinas y los cambios tempranos de la composición de la MEC.

La perpetuación corresponde a los acontecimientos celulares que amplifican el fenotipo activado por medio de los efectos crecientes de las diversas citocinas, y comprende la proliferación, fibrogénesis, contractilidad, realización de citocinas, quimiotaxis y motilidad celular, pérdida de los retinoides y regulación de la MEC. Esta etapa es el resultado de estímulos autocrinos y paracrinos, así como de la remodelación acelerada de la MEC.

\section{REPERCUSIÓN DE LOS CAMBIOS FENOTÍPICOS DE LAS CÉLULAS ESTRELLADAS DEL HÍGADO ACTIVADAS EN LA FIBROSIS HEPÁTICA}

Como ya se ha mencionado, la activación de las CEH conduce a varias modificaciones fenotípicas que lógicamente repercuten en el desarrollo de la fibrosis hepática.

\section{Producción de la matriz intersticial}

Normalmente la MEC del hígado consta de variadas sustancias colágenas y no colágenas cuyas composición y concentración son responsabilidad de las CEH. Estos componentes intercelulares son elementos esenciales para mantener la morfología y las funciones de las células del hígado y, como es obvio, sus alteraciones en términos cualitativos y/o cuantitativos determinan modificaciones patológicas tanto desde el punto de vista morfológico como funcional.

Como ya hemos adelantado, en la lesión hepatocelular las $\mathrm{CEH}$ sufren un proceso de transdiferenciación fenotípica a miofibroblastos. Estos «nuevos» miofibroblastos constituyen una «nueva» fuente de múltiples tipos de proteínas colágenas y no colágenas de la MEC, como el colágeno tipo I, tipo III, tipo IV, laminina, elastina, fibronectina y diversos proteoglucanos como la condroitinsulfato, el dermatansulfato y el heparansulfato. Por ejemplo, en las primeras etapas de la lesión hepatocelular ya existe una creciente deposición de colágeno tipo III, tipo IV y fibronectina en el espacio de Disse; no obstante, en el hígado cirrótico la cantidad de la MEC depositada por los miofibroblastos puede ser más de 6 veces la del hígado normal. Muchas sustancias y agentes fibrogénicos provenientes de las células inflamatorias y de las células hepáticas, entre ellas las $\mathrm{CEH}$, se liberan durante el proceso inflamatorio, donde actúan de forma paracrina y autocrina sobre las CEH y contribuyen a mediar y mantener el proceso fibrogénico. Uno de los más importantes y potentes mediadores profibrogénicos en la lesión hepática es el ya mencionado TGF- $\beta^{34-36}$. Éste es un factor de crecimiento ampliamente distribuido en el organismo y regula no sólo la deposición de la MEC como parte de la respuesta normal a la lesión tisular, sino que también es un mediador de gran importancia en la fibrosis patológica ${ }^{37}$. El TGF- $\beta$ pertenece a una familia de péptidos multifuncionales llamada superfamilia del TGF- $\beta$, que integra más de 30 citocinas, entre las cuales se incluyen las 5 isoformas del TGF- $\beta, 3$ de las cuales se identificaron en los mamíferos $(\text { TGF- } \beta 1 \text {, TGF- } \beta 2 \text { y TGF- } \beta 3)^{38}$. Ejercen sus acciones a través de una familia de receptores membranosos tipos I y II de actividad proteincinasa intrínseca ${ }^{38,39}$. En el hígado estas 3 isoformas se encuentran presentes, aunque parece que el TGF- $\beta 1$ es el de mayor importancia ${ }^{34,40}$ y tiene un papel muy destacado en la fibrogénesis hepática. El TGF- $\beta$ es sintetizado principalmente por las $\mathrm{CEH}$, donde produce de forma autocrina sus principales efectos fibrogénicos ${ }^{34}$. Los estudios in vitro e in vivo demuestran que el TGF- $\beta$ provoca en las CEH activadas un aumento de la síntesis de las fibras colágenas, que se depositan progresivamente en el espacio intercelular y en el espacio de Disse, lo que altera la función y la homeostasis de las células hepáticas ${ }^{41,42}$. Asimismo estimula la síntesis de los componentes de la membrana basal, lo que conduce a la «capilarización» de los sinusoides (véase más adelante) ${ }^{43,44}$. En ratas transgénicas, la sobreexpresión del TGF- $\beta 1$ puede inducir la fibrosis, mientras que la fibrosis experimental puede inhibirse con anticuerpos neutralizantes ${ }^{45,46}$. En la actualidad está 
ampliamente aceptado que la persistente estimulación autocrina de las CEH por el TGF- $\beta$ es un mecanismo clave en el desarrollo de la fibrogénesis hepática ${ }^{34}$. Sin embargo, este concepto aún sigue en discusión.

\section{Inhibición de la degradación de la matriz extracelular}

La progresión de la fibrosis hepática se asocia no sólo a la excesiva producción de la MEC, sino además a una importante inhibición anormal de su degradación. Como hemos recordado antes, las MMP son un grupo de enzimas que se encargan de catalizar los componentes de la MEC. Los TIMP pueden bloquear las actividades catalíticas de estas enzimas a fin de mantener en condiciones normales un equilibrio fisiológico entre la síntesis y la degradación de los componentes de la MEC.

Dentro de las MMP cabe mencionar las colagenasas, que degradan los colágenos intersticiales (tipos I, II y III); las gelatinasas, que se encargan de catalizar componentes de la membrana basal, y las estromalisinas, que hacen lo mismo sobre un amplia serie de sustancias como los proteoglucanos, la laminina, etc. ${ }^{47-49}$. Todas esas MMP son sintetizadas por diferentes tipos de células hepáticas ${ }^{50}$, mientras que el TIMP-1 y el TIMP-2, que son los 2 inhibidores de las MMP más importantes y estudiados hasta el momento, se expresan únicamente en la $\mathrm{CEH}^{51,52}$. Estas moléculas en conjunto son de mucha importancia no sólo en la fisiología de la remodelación y reparación de la MEC, sino también en el desarrollo del proceso fibrogénico.

En cultivo primario de CEH, la expresión de MMP como las colagenasas y las estromalisinas aumenta transitoriamente en la primera etapa del cultivo, para luego disminuir hasta volverse indetectable, mientras que tanto la expresión del TIMP-1 como la del TIMP-2 aumentan llamativa y progresivamente en dicho cultivo ${ }^{53-55}$. En modelos experimentales de animales con fibrosis hepática inducida por medio de la ligación del conducto biliar o el tetracloruro de carbono (CCl4), la expresión del TIMP-1 y del TIMP-2 aumenta significativamente entre las 3 y $6 \mathrm{~h}$ después de haberse producido la lesión hepatocelular, para luego permanecer en aumento progresivo a lo largo de la fase crónica de dichos modelos ${ }^{52,55}$.

En pacientes con enfermedades hepáticas crónicas como la colangitis esclerosante, la cirrosis biliar primaria, la hepatitis crónica autoinmunitaria activa y la atresia biliar existe un importante aumento de las concentraciones tisulares de TIMP-1, TIMP-2 o ambos; dichos valores pueden ser 5 veces más elevados que en el hígado normal ${ }^{5,56}$, lo que indicaría que la expresión de los TIMP por las CEH favorece aún más el depósito del tejido fibroso.

\section{Capilarización de los sinusoides}

Durante el proceso fibrogénico, el sistema microvascular hepático se modifica: de un sistema sinusoidal de capilares discontinuos, pasa a ser un sistema de capilares continuos; es lo que se denomina «capilarización» ${ }^{57-60}$. Hay un aumento de la producción de colágeno tipo IV, laminina y entactina que se depositan en el espacio de Disse, donde forman una membrana basal verdadera ${ }^{61,62}$. Las observaciones al microscopio electrónico revelan una importante disminución de las fenestraciones endoteliales tanto en número como en tamaño (defenestración) y la formación clara de una membrana basal verdadera de ubicación subendotelial ${ }^{63}$. Algunos autores incluyen, como una etapa siguiente a la capilarización, la «venulización», que se define como la transformación de los sinusoides en vénulas mediante el aumento de su diámetro, la pérdida de las fenestraciones y la formación de una membrana basal subyacente $^{64}$. Como normalmente muchas funciones hepáticas dependen del intercambio rápido y bidireccional de macromoléculas entre el plasma y los hepatocitos, la capilarización altera la difusión y la filtración de sustancias bioactivas entre estos 2 compartimentos.

\section{Contracción de las células estrelladas del hígado y regulación del flujo sanguíneo sinusoidal}

Las CEH presentan características morfológicas, ultraestructurales y funcionales similares a los pericitos, que participan en la regulación del flujo sanguíneo microvascular en diversos órganos ${ }^{65-67}$. Las CEH adoptan una estratégica ubicación perisinusoidal; extienden a partir de sus cuerpos celulares varias prolongaciones primarias de $20 \mu \mathrm{m}$ de longitud que corren a lo largo de uno o más sinusoides. De estas prolongaciones primarias surgen perpendicularmente prolongaciones secundarias, que tienden a rodear los sinusoides de forma circular, lo que apuntaría a un posible e interesante papel de las CEH en el control del flujo sanguíneo ${ }^{15,17}$. Estudios con microscopia intravital de hígados aislados de rata revelan que las CEH pueden mediar el diámetro sinusoidal en presencia de mediadores vasoactivos ${ }^{68}$. Además, se ha demostrado in vitro que la contracción y relajación de las CEH se producen efectivamente en respuesta a diversos mediadores vasoactivos como las endotelinas, la angiotensina II, el óxido nítrico (NO) y el péptido natriurético arterial, entre otros ${ }^{69-72}$. Pero, más allá de estos datos, aún no existen claras evidencias de la participación de las CEH en el control de la perfusión del hígado en condiciones fisiológicas. Sin embargo, cuando hay fibrosis hepática patológica, parece que las CEH influyen activamente en el manejo del flujo sanguíneo sinusoidal y, por lo tanto, en la fisiopatología de la hipertensión portal. La aparición de estructuras contráctiles como los cuerpos densos y la actina alfa del músculo liso ${ }^{73,74}$, las modificaciones del microambiente por los cambios de la MEC, que conduce a una mayor tensión citosquelética ${ }^{75,76}$, y la aparición de una importante expresión de canales de calcio dependientes de voltaje en las CEH activadas, que favorecen un importante incremento de la concentración de $\mathrm{Ca}^{2+}$ intracelular, seguido por la contracción celular ${ }^{77,78}$, son algunas de las evidencias ultraestructurales que sostienen lo anterior. Estas modificaciones se observan sólo en las CEH activadas, no en las quiescentes. 


\section{Principales estimulantes de la contracción de las células estrelladas del hígado}

Endotelinas. Son de los vasoconstrictores más potentes conocidos hasta ahora. Se han identificado 3 tipos de esa familia (endotelinas 1, 2 y 3), que actúan sobre 2 tipos de receptores: los receptores tipo A y los receptores tipo $\mathrm{B}^{79,80}$. De estas 3 isoformas, la endotelina- 1 es la más estudiada en el hígado. Se sintetiza mayoritariamente por las CEH y actúa en diversas células hepáticas, aunque los receptores de las endotelinas abundan claramente en las CEH activadas ${ }^{81,82}$. A través de los receptores A, la endotelina-1 produce en las $\mathrm{CEH}$ un aumento transitorio de la concentración de $\mathrm{Ca}^{2+}$ intracelular (más de 8 veces por encima de los valores basales) unido a un reversible proceso de contracción celular. In vitro se produce la contracción del 78, el 55, el 59 y el $56 \%$ de las CEH después de exponerlas a $10 \mathrm{nM}$ de endotelina-1 durante 2, 5, 10 y $20 \mathrm{~min}$, respectivamente, en contraste con la relajación del 82 , el 83 y el $71 \%$ de las CEH contraídas después de añadir $500 \mu \mathrm{M}$ de nitroprusiato de sodio $^{72}$.

La estimulación de estas células con endotelina-1 produce su contracción dentro de $10 \mathrm{~s}$ y alcanza una fuerza máxima de contracción en 5 min, mientras que al retirar esa sustancia del medio la relajación completa o casi completa de las CEH se da dentro de $45 \min ^{17}$. También la endotelina- 1 disminuye el diámetro sinusoidal en un $25 \%$ y aumenta el gradiente de presión sinusoidal en un $116 \%$ y la resistencia vascular en un $350 \%$ en hígados aislados de ratas observados con microscopia intravital $^{68}$. En el modelo de hígado de rata aislado y perfundido, la infusión de la endotelina-1 provoca, de forma dependiente de la dosis, un aumento de la presión portal asociado a un notable incremento de la glucogenólisis y del consumo de oxígeno ${ }^{83}$. Es importante tener en cuenta que la contractilidad de las CEH inducida por la endotelina-1 aumenta progresivamente a medida que avanza la lesión hepática y es directamente proporcional al grado de activación de las $\mathrm{CEH}$, siendo más prominente en la cirrosis ${ }^{84}$. Los antagonistas de los receptores A y B de la endotelina pueden disminuir la presión portal en animales con hipertensión portal por un efecto inhibitorio sobre la contracción de las $\mathrm{CEH}^{85}$.

Angiotensina II. Desempeña un papel importante en la vasoconstricción por la interacción con el receptor de la angiotensina $\mathrm{I}^{86}$.

En las CEH activadas existe una alta expresión de los componentes del sistema renina-angiotensina, tales como la renina activa, la enzima de conversión de la angiotensina y la angiotensina $\mathrm{II}^{87-90}$. La interacción de la angiotensina II con la angiotensina I provoca varias acciones y efectos de mucha importancia fisiopatológica; de ellos, uno de los más importantes es el incremento, dependiente de la dosis, de la concentración del $\mathrm{Ca}^{2+}$ intracelular, con estimulación de la contracción celular, lo que produce hipertensión portal. Los antagonistas de la angiotensina II como el losartán bloquean estas acciones y mejoran la hi-
TABLA I. Algunos de los agentes vasoactivos más estudiados que actúan en las células estrelladas del hígado

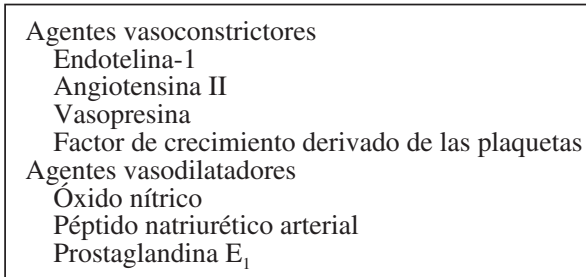

pertensión portal ${ }^{91-93}$. Todas estas observaciones apenas pueden detectarse en las CEH quiescentes.

Hormona antidiurética. Es un potente vasopresor producido por la neurohipófisis y actúa sobre receptores específicos $\mathrm{V}_{1}, \mathrm{~V}_{2} \mathrm{y} \mathrm{V}_{3}{ }^{94}$. En el hígado produce diversos efectos sobre los receptores $\mathrm{V}_{1}$, recientemente identificados en las $\mathrm{CEH}^{95}$. Estos efectos son muy similares a los observados sobre las células del músculo liso vascular, tales como el aumento de la concentración del $\mathrm{Ca}^{2+}$ intracelular y el estímulo de la contracción celular de forma dependiente de la dosis. Estos efectos pueden bloquearse por medio de antagonistas del receptor $\mathrm{V}_{1}$.

\section{Principales relajantes de la contracción de las células estrelladas del hígado}

Fisiológicamente, la contracción de las CEH queda contrarrestada por los efectos de agentes vasorrelajantes como el NO, el péptido natriurético arterial, entre otras sustancias que se detallan en la tabla I. De estos mediadores, el más estudiado es el NO, que participa en diversos procesos como la regulación del tono vascular, la neurotransmisión y la citotoxicidad mediada por células ${ }^{96-98}$. Se sintetiza por la conversión de la L-arginina a L-citrulina por medio de la NO sintetasa ${ }^{99,100}$.

En el hígado, estudios in vitro e in vivo revelan que el NO es sintetizado en el endotelio por la NO sintetasa constitutiva. Se ha observado un aumento de la presión portal en animales que reciben de forma intraperitoneal un inhibidor específico de la biosíntesis del NO (el N- $\omega$-nitro-Larginina), y por ello se ha relacionado el NO con la regulación de la circulación portal intrahepática en el lecho vascular del hígado normal de ratas ${ }^{101}$. La microcirculación en el hígado cirrótico se caracteriza por la disfunción endotelial provocada por la menor liberación de factores endoteliales relajantes, entre ellos el NO, lo que produce una menor vasodilatación y un significativo aumento de la resistencia intrahepática en pacientes con hipertensión portal $^{102}$. Otros estudios demuestran que la lesión hepatocelular conduce a un aumento de la producción de la endotelina-1 y a una disminución de la síntesis del NO; este fenómeno favorece la constricción de los sinusoides y las paredes vasculares por la actividad contráctil de las CEH y las células musculares lisas, respectivamente, lo que contribuye a un incremento en la resistencia intrahepática y de la presión portal ${ }^{102}$. 
SAREM M, ET AL. LAS CÉLULAS ESTRELLADAS DEL HÍGADO: SU IMPORTANCIA EN CONDICIONES NORMALES Y PATOLÓGICAS

TABLA II. Agentes con actividad antifibrótica hepática

\begin{tabular}{|c|c|c|}
\hline Componente & Comentarios & Referencia \\
\hline $\begin{array}{l}\text { Gliotoxina: una de las toxinas producidas } \\
\text { por Aspergillus fumigatus }\end{array}$ & $\begin{array}{l}\text { Induce la apoptosis de las CEH } \\
\text { Posee un efecto inmunodepresor }\end{array}$ & $\begin{array}{l}\text { Orr JG, et al. Hepatology. 2004;40:232-42 } \\
\text { Kweon YO, et al. J Hepatol. 2003;39:38-46 } \\
\text { Wright MC, et al. Gastroenterology.2001; } \\
\text { 121:685-98 } \\
\text { Sutton P, et al. Infect Immun. 1994;62:1192-8 }\end{array}$ \\
\hline $\begin{array}{l}\text { Stephania tetrandra (Fang Ji): hierba } \\
\text { medicinal tradicional china }\end{array}$ & $\begin{array}{l}\text { Induce la apoptosis de las CEH } \\
\text { Efecto antioxidante } \\
\text { Induce la reducción de la presión venosa portal }\end{array}$ & $\begin{array}{l}\text { Zhao YZ, et al. Phytother Res. 2004;18:306-9 } \\
\text { Park PH, et al. Pharmacol Toxicol. 2000; } \\
\text { 87:261-8 } \\
\text { Huang YT, et al. Planta Med. 1999;65:130-4 }\end{array}$ \\
\hline $\begin{array}{l}\text { Salvia miltiorrhiza: hierba medicinal } \\
\text { tradicional china }\end{array}$ & $\begin{array}{l}\text { Inhibe la proliferación de las CEH } \\
\text { Disminuye la activación de las CEH } \\
\text { y la expresión de proteínas de la MEC } \\
\text { por el TGF- } \beta 1 \\
\text { Induce la apoptosis de las CEH }\end{array}$ & $\begin{array}{l}\text { Kim JY, et al. Pharmacol Toxicol. 2003;92: } \\
\text { 195-200 } \\
\text { Liu C, et al. Zhonghua Yi Xue Za Zhi. 2002; } \\
\text { 82:1267-72 } \\
\text { Nan JX, et al. J Pharm Pharmacol. 2001;53: } \\
\text { 197-204 }\end{array}$ \\
\hline $\begin{array}{l}\text { Colchicina: inhibidor del ensamblaje } \\
\text { de microtúbulos }\end{array}$ & $\begin{array}{l}\text { Incrementa la actividad de la colagenasa } \\
\text { Interviene en el movimiento transcelular } \\
\text { del colágeno al inhibir el ensamblaje } \\
\text { de los microtúbulos en las CEH } \\
\text { Inhibe la migración de los leucocitos }\end{array}$ & $\begin{array}{l}\text { Tapalaga D, et al. Med Intern. 1986;24:69-73 } \\
\text { Kershenobich D, et al. Gastroenterology. 1979; } \\
\text { 77:532-6 }\end{array}$ \\
\hline Interferón gamma & $\begin{array}{l}\text { Inhibe la activación de las CEH y la producción } \\
\text { de la MEC }\end{array}$ & $\begin{array}{l}\text { Weng HL, et al. World J Gastroenterol. 2001; } \\
\text { 7:42-8 } \\
\text { Rockey DC, et al. J Investig Med. 1994;42: } \\
\quad 660-70\end{array}$ \\
\hline Interferón alfa: agente antiviral & $\begin{array}{l}\text { Inhibe la proliferación de las CEH, favorece } \\
\text { la degradación del colágeno al activar } \\
\text { las colagenasas y reduce la expresión } \\
\text { del TGF- } \beta 1 \\
\text { Reduce la inflamación del hígado } \\
\text { Reduce el riesgo del desarrollo del carcinoma } \\
\text { hepatocelular }\end{array}$ & $\begin{array}{l}\text { Yagura M, et al. J Gastroenterol. 2000;35: } \\
\text { 105-11 } \\
\text { Fort J, Pilette C, et al. J Hepatol. 1998;29: } \\
\text { 263-70 } \\
\text { Rodríguez-Fragoso L, et al. Pharmacology. } \\
\text { 1995;51:341-6 }\end{array}$ \\
\hline $\begin{array}{l}\text { Silimarina: extracto de plantas estandarizado } \\
\text { de efecto protector hepático }\end{array}$ & $\begin{array}{l}\text { Disminuye los valores del ARN mensajero } \\
\text { del procolágeno } \alpha 1(\mathrm{I}) \text {, TIMP-1 y TGF- } \beta 1\end{array}$ & $\begin{array}{l}\text { Jia JD, et al. J Hepatol. 2001;35:392-8 } \\
\text { Boigk G, et al. Hepatology. 1997;26:643-9 }\end{array}$ \\
\hline Inhibidores del sistema renina-angiotensina & $\begin{array}{l}\text { Bloquean la expresión del TGF- } \beta 1 \\
\text { Inhiben la proliferación y la contracción } \\
\text { de las CEH } \\
\text { Inhiben la síntesis de colágeno por las CEH }\end{array}$ & $\begin{array}{l}\text { Yoshiji H, et al. Hepatology. 2001;34:745-50 } \\
\text { Kurikawa N, et al. Br J Pharmacol. 2003;139: } \\
\text { 1085-94 } \\
\text { Baik SK, et al. Korean J Gastroenterol. 2003; } \\
\text { 42:134-41 }\end{array}$ \\
\hline Agonistas del PPAR- $\gamma$ & $\begin{array}{l}\text { Inhiben la activación, proliferación y } \\
\text { quimiotaxis de las CEH y su capacidad } \\
\text { de producir colágeno } \\
\text { Inhiben la inflamación del hígado }\end{array}$ & $\begin{array}{l}\text { Marra F, et al. Gastroenterology. 2000;119: } \\
\text { 466-78 } \\
\text { Kon K, et al. Biochem Biophys Res Commun. } \\
\text { 2002;291:55-61 } \\
\text { Galli A, et al. Gastroenterology. 2002;122: } \\
\quad 1924-40\end{array}$ \\
\hline
\end{tabular}

CEH: células estrelladas; MEC: matriz extracelular; TGF- $\beta 1$ : factor transformador de crecimiento $\beta-1$; TIMP-1: inhibidor tisular-1 de metaloproteinasas; PPAR: receptores del proliferador-activador de peroxisomas.

\section{NOCIONES GENERALES SOBRE LAS FUTURAS ESTRATEGIAS TERAPÉUTICAS}

Las $\mathrm{CEH}$ han sido un atractivo e interesante blanco para el desarrollo de agentes antifibróticos que puedan resolver el problema de la fibrosis y cirrosis hepáticas. Muchos científicos han planificado interesantes líneas de investigación como, por ejemplo, reducir el proceso inflamatorio y la respuesta inmunitaria, inhibir la activación de las $\mathrm{CEH}$, inducir la apoptosis de las CEH activadas, bloquear la actividad fibrogénica, contráctil, proliferativa y proinflamatoria de las $\mathrm{CEH}$, disminuir la síntesis de los componentes de la MEC y/o favorecer su degradación ${ }^{103}$. En la tabla II se mencionan algunos de los más importantes componentes «antifibrogénicos» en estudio.
La carencia de marcadores séricos establecidos para evaluar la respuesta hepática a los fármacos en estudio obliga al investigador a realizar varias biopsias hepáticas a los pacientes cirróticos en tratamiento, lo que es poco agradable para el paciente ${ }^{104}$. La falta de selectividad celular in vivo de los fármacos que muestran un efecto antifibrótico in vitro es otro importante problema de los medicamentos en uso, que pueden terminar produciendo importantes efectos secundarios, como la apoptosis de los macrófagos $\mathrm{y}$ linfocitos $\mathrm{T}$ por el uso de la gliotoxina ${ }^{105}$, el riesgo de desarrollar enfermedades autoinmunitarias y neoplásicas por el empleo de antagonistas del TGF- $\beta^{106,107}$, el riesgo de desarrollar tumores malignos por el uso de los agonistas de los receptores del proliferador-activador de peroxisomas ${ }^{108,109}$, etc. Surge entonces la necesidad de crear fár- 
macos antifibróticos «inteligentes» que puedan actuar selectivamente en las $\mathrm{CEH}$ activadas.

\section{BIBLIOGRAFÍA}

1. Wake K. Karl Wilhelm Kupffer and his contributions to modern hepatology comparative. Hepatology. 2004;3 Suppl 1:2.

2. Ramadori G. The stellate cell (Ito-cell, fat-storing cell, lipocyte, perisinusoidal cell) of the liver. New insights into pathophysiology of an intriguing cell. Virchows Arch B Cell Pathol Incl Mol Pathol. 1991;61:147-58.

3. Eastman JT, DeVries AL. Hepatic ultrastructural specialization in Antarctic fishes. Cell Tissue Res. 1981;219:489-96.

4. Crawford JM. Hígado y vías biliares. En: Cotran RS, Kumar V, Robbins SL, editores. Patología estructural y funcional. 5. ${ }^{\mathrm{a}}$ ed. Madrid: McGraw-Hill Interamericana de España S.A.; 1995. p. 919-91.

5. Geerts A, Schuppan D, Lazeroms S, De Zanger R, Wisse E. Collagen type I and III occur together in hybrid fibrils in the space of Disse of normal rat liver. Hepatology. 1990;12:23341.

6. Bioulac-Sage P, Lafon ME, Saric J, Balabaud C. Nerves and perisinusoidal cells in human liver. J Hepatol. 1990;10:10512.

7. Griffiths MR, Keir S, Burt AD. Basement membrane proteins in the space of Disse: a reappraisal. J Clin Pathol. 1991;44: 646-8.

8. Senoo H. Structure and function of hepatic stellate cells. Med Electron Microsc. 2004;37:3-15.

9. Safadi R, Friedman SL. Hepatic fibrosis-role of hepatic stellate cell activation. Med Gen Med. 2002;4:27.

10. Geerts A. History, heterogeneity, developmental biology, and functions of quiescent hepatic stellate cells. Semin Liver Dis. 2001;21:311-35.

11. Suematsu M, Asio S. Professor Toshio Ito: a clairvoyant in pericyte biology. Keio J Med. 2001;50:66-71.

12. Blomhoff R, Rasmussen M, Nilsson A, Norum KR, Berg T, Blaner WS, et al. Hepatic retinol metabolism. Distribution of retinoids, enzymes, and binding proteins in isolated rat liver cells. J Biol Chem. 1985;260:13560-5.

13. Yamada M, Blaner WS, Soprano DR, Dixon JL, Kjeldbye HM, Goodman DS. Biochemical characteristics of isolated rat liver stellate cells. Hepatology. 1987;7:1224-9.

14. Nagy NE, Holven KB, Roos N, Senoo H, Kojima N, Norum $\mathrm{KR}$, et al. Storage of vitamin A in extrahepatic stellate cells in normal rats. J Lipid Res. 1997;38:645-58.

15. Sato M, Suzuki S, Senoo H. Hepatic stellate cell: unique characteristics in cell biology and phenotype. Cell Struct Funct. 2003;28:105-12.

16. Kawada N. The hepatic perisinusoidal stellate cell. Histol Histpathol. 1997;12:1069-80.

17. Thimgan MS, Yee HF Jr. Quantitation of rat hepatic stellate cell contraction: stellate cells' contribution to sinusoidal resistance. Am J Physiol. 1999;277:G137-G43.

18. Solis Herruzo JA. Factores involucrados en la fibrogénesis hepática. Gastroenterol Hepatol. 2000;26:186-99.

19. Pinzani M, Marra F. Cytokine receptors and signaling in hepatic stellate cells. Semin Liver Dis. 2001;21:397-416.

20. Benlloch S, Beltrán B, Moreno R, Berenguer M. Fibrogénesis y trasplante hepático. Gastroenterol Hepatol. 2003;26:381-95.

21. Gressner AM, Bachem MG. Cellular sources of noncollagenous matrix proteins: role of fat-storing cells in fibrogenesis. Semin Liver Dis. 1990;10:30-46.

22. Hautekeete ML, Geerts A. The hepatic stellate (Ito) cell: its role in human liver disease. Virchows Arch. 1997;430:195207.

23. Bonis PA, Friedman SL, Kaplan MM. Is liver fibrosis reversible? N Engl J Med. 2001;344:452-4.

24. Friedman SL. Molecular regulation of hepatic fibrosis, an integrated cellular response to tissue injury. J Biol Chem. 2000; 275:2247-50

25. Iredale JP. Tissue inhibitors of metalloproteinases in liver fibrosis. Int J Biochem Cell Biol. 1997;29:43-54.
26. Arthur MJ, Mann DA, Iredale JP. Tissue inhibitors of metalloproteinases, hepatic stellate cells and liver fibrosis. J Gastroenterol Hepatol. 1998;13 Supl:33-8.

27. Gressner AM. Transdifferentiation of hepatic stellate cells (Ito cells) to myofibroblasts: a key event in hepatic fibrogenesis. Kidney Int Suppl. 1996;54:S39-S45.

28. Casu A, Canepa M, Nanni G. Perisinusoidal stellate cells or Ito cells and their role in hepatic fibrosis. Pathologica. 1994; $86: 467-99$.

29. Joya-Vázquez PP, Bruguera M, Sánchez-Tapias JM, Ampurdanés S, Ventura PJ. La progresión de la fibrosis hepática en la hepatitis C crónica. Gastroenterol Hepatol. 2000;23:1-6.

30. Enzan H, Himeno H, Saibara T, Hara H. Recent studies on Ito cells with molecular biology. Nippon Rinsho. 1993;51:47281.

31. García Buey L, García Monzon C, Moreno Otero R. Los mediadores de la inflamación y la hepatitis crónica. Gastroenterol Hepatol. 1995; 18:42-54.

32. Pinzani M, Marra F, Carloni V. Signal transduction in hepatic stellate cells. Liver. 1998;18:2-13.

33. Li D, Friedman SL. Liver fibrogenesis and the role of hepatic stellate cells: new insights and prospects for therapy. J Gastroenterol Hepatol. 1999;14:618-33.

34. Gressner AM, Weiskirchen R, Breitkopf K, Dooley S. Roles of TGF-beta in hepatic fibrosis. Front Biosci. 2002;7:793-807.

35. Casini A, Pinzani M, Milani S, Grappone C, Galli G, Jezequel $\mathrm{AM}$, et al. Regulation of extracellular matrix synthesis by transforming growth factor beta 1 in human fat-storing cells. Gastroenterology. 1993; 105:245-53.

36. Hellerbrand C, Stefanovic B, Giordano F, Burchardt ER, Brenner DA. The role of TGFbeta1 in initiating hepatic stellate cell activation in vivo. J Hepatol. 1999;30:77-87.

37. Border WA, Noble NA. Transforming growth factor $b$ in tissue fibrosis. N Engl J Med. 1994;331:1286-92.

38. Wells RG. Fibrogenesis V. TGF- $\beta$ signaling pathways. Am J Physiol Gastrointest Liver Physiol. 2000;279:G845-G50.

39. Massague J, Chen YG. Controlling TGF-beta signaling. Genes Dev. 2000;14:627-44.

40. Bachem MG, Meyer D, Melchior R, Sell KM, Gressner AM. Activation of rat liver perisinusoidal lipocytes by transforming growth factors derived from myofibroblastlike cells. A potential mechanism of self perpetuation in liver fibrogenesis. J Clin Invest. 1992;89:19-27.

41. Bachem MG, Sell KM, Melchior R, Kropf J, Eller T, Gressner AM. Tumor necrosis factor alpha (TNF alpha) and transforming growth factor beta 1 (TGF beta 1) stimulate fibronectin synthesis and the transdifferentiation of fat-storing cells in the rat liver into myofibroblasts. Virchows Arch B Cell Pathol Incl Mol Pathol. 1993;63:123-30.

42. Hellerbrand C, Stefanovic B, Giordano F, Burchardt ER, Brenner DA. The role of TGFbeta1 in initiating hepatic stellate cell activation in vivo. J Hepatol. 1999;30:77-87.

43. Chai Q, Krag S, Miner JH, Nyengaard JR, Chai S, Wogensen L. TGF-beta1 induces aberrant laminin chain and collagen type IV isotype expression in the glomerular basement membrane. Nephron Exp Nephrol. 2003;94:e123-e36.

44. Neubauer K, Kruger M, Quondamatteo F, Knittel T, Saile B, Ramadori G. Transforming growth factor-beta1 stimulates the synthesis of basement membrane proteins laminin, collagen type IV and entactin in rat liver sinusoidal endothelial cells. J Hepatol. 1999;31:692-702.

45. Kanzler S, Lohse AW, Keil A, Henninger J, Dienes HP, Schirmacher P, et al. TGF-beta in liver fibrosis: an inducible transgenic mouse model to study liver fibrogenesis Am J Physiol. 1999;276:G1059-G68.

46. Moller-Pedersen T, Cavanagh HD, Petroll WM, Jester JV. Neutralizing antibody to TGFbeta modulates stromal fibrosis but not regression of photoablative effect following PRK. Curr Eye Res. 1998;17:736-47.

47. Arthur MJ. Fibrogenesis II. Metalloproteinases and their inhibitors in liver fibrosis. Am J Physiol Gastrointest Liver Physiol. 2000;279:G245-G9.

48. Benyon RC, Arthur MJ. Extracellular matrix degradation and the role of stellate cells. Semin Liver Dis. 2001;21:373-84.

49. Knittel T, Mehde M, Kobold D, Saile B, Dinter C, Ramadori G. Expression patterns of matrix metalloproteinases and their 
inhibitors in parenchymal and non parenchymal cell of rat liver. Regulation by TNF- $\alpha$ and TGF- $\beta 1$. J Hepatol. 1999;30: 48-60.

50. McCrudden R, Iredale JP. Liver fibrosis, the hepatic stellate cell and tissue inhibitors of metalloproteinases. Histol Histopathol. 2000;15:1159-68.

51. Sakaida I, Hironaka K, Kimura T, Terai S, Yamasaki T, Okita K. Herbal medicine Sho-saiko-to (TJ-9) increases expression matrix metalloproteinases (MMPs) with reduced expression of tissue inhibitor of metalloproteinases (TIMPs) in rat stellate cell. Life Sci. 2004;74:2251-63.

52. Herbst H, Wege T, Milani S, Pellegrini G, Orzechowski HD, Bechstein WO, et al. Tissue inhibitor of metalloproteinases-1 and 2 RNA expression in rats and human liver fibrosis. Am J Pathol. 1997; 150:1647-59.

53. Iredale JP, Murphy G, Hembry RM, Friedman SL, Arthur MJ. Human hepatic lipocytes synthesize tissue inhibitor of metalloproteinases-1. Implications for regulation of matrix degradation in liver. J Clin Invest. 1992;90:282-7.

54. Iredale JP, Goddard S, Murphy G, Benyon RC, Arthur MJ. Tissue inhibitor of metalloproteinase-1 and interstitial collagenase expression in autoimmune chronic active hepatitis and activated human hepatic lipocytes. Clin Sci (Lond). 1995;89: 75-81.

55. Iredale JP, Benyon RC, Arthur MJ, Ferris WF, Alcolado R, Winwood PJ, et al. Tissue inhibitor of metalloproteinase-1 messenger RNA expression is enhanced relative to interstitial collagenase messenger RNA in experimental liver injury and fibrosis. Hepatology. 1996;24:176-84.

56. Benyon RC, Iredale JP, Goddard S, Winwood PJ, Arthur MJP. Expression of tissue inhibitor of metalloproteinases-1 and -2 is increased in fibrotic human liver. Gastroenterology. 1996;110:821-31.

57. Huet PM, Villeneuve JP, Pomier-Layrargues G, Marleau D. Hepatic circulation in cirrhosis. Clin Gastroenterol. 1985;14: 155-68.

58. Griffiths MR, Keir S, Burt AD. Basement membrane proteins in the space of Disse: a reappraisal. J Clin Pathol. 1991;44: 646-8.

59. Martínez-Hernández A, Martínez J. The role of capillarization in hepatic failure: studies in carbon tetrachloride-induced cirrhosis. Hepatology. 1991;14:864-74.

60. Zimmermann A, Zhao D, Reichen J. Myofibroblasts in the cirrhotic rat liver reflect hepatic remodeling and correlate with fibrosis and sinusoidal capillarization. J Hepatol. 1999;30: 646-52.

61. Neubauer K, Saile B, Ramadori G. Liver fibrosis and altered matrix synthesis. Can J Gastroenterol. 2001;15:187-93.

62. Xiao W, Wang Y, Liu X. The coordinated expression of laminin and its integrin receptor in hepatic sinusoidal capillarization. Zhonghua Nei Ke Za Zhi. 2001;40:618-20.

63. Urashima S, Tsutsumi M, Nakase K, Wang JS, Takada A. Studies on capillarization of the hepatic sinusoids in alcoholic liver disease. Alcohol Alcohol Suppl. 1993;1B:77-84.

64. Bhunchet E, Fujieda K. Capillarization and venularization of hepatic sinusoids in porcine serum-induced rat liver fibrosis: a mechanism to maintain liver blood flow. Hepatology. 1993; 18:1450-8

65. Rockey D. The cellular pathogenesis of portal hypertension: stellate cell contractility, endothelin, and nitric oxide. Hepatology. 1997;25:2-5.

66. Kelley C, D'Amore P, Hechtman HB, Shepro D. Microvascular pericyte contractility in vitro: comparison with other cells of the vascular wall. J Cell Biol. 1987;104:483-90.

67. Rockey DC. Hepatic blood flow regulation by stellate cells in normal and injured liver. Semin Liver Dis. 2001;21:337-49.

68. Zhang JX, Pegoli W Jr, Clemens MG. Endothelin-1 induces direct constriction of hepatic sinusoids. Am J Physiol. 1994; 266(4 Pt 1):G624-32.

69. Reynaert H, Thompson MG, Thomas T, Geerts A. Hepatic stellate cells: role in microcirculation and pathophysiology of portal hypertension. Gut. 2002;50:571-81

70. McCuskey RS. Morphological mechanisms for regulating blood flow through hepatic sinusoids. Liver. 2000;20:3-7.

71. Clemens MG, Zhang JX. Regulation of sinusoidal perfusion: in vivo methodology and control by endothelins. Semin Liver Dis. 1999; 19:383-96.
72. Kawada N, Tran-Thi TA, Klein H, Decker K. The contraction of hepatic stellate (Ito) cells stimulated with vasoactive substances. Possible involvement of endothelin 1 and nitric oxide in the regulation of the sinusoidal tonus. Eur $\mathrm{J}$ Biochem. 1993:213:815-23

73. Ramadori G, Veit TH, Shwogler S, Dienes HP, Knittel T, Rieder $\mathrm{H}$, et al. Expression of the gene of a-smooth muscle actin isoform in rat liver and in rat fat-storing (ITO) cells. Virchows Arch B Cell Pathol Incl Mol Pathol. 1990;59:349-57.

74. Schmitt-GrAff A, Krüger S, Bochard F, Gabbiani G, Denk H. Modulation of alpha smooth muscle actin and desmin expression in perisinusoidal cells of normal and diseased human livers. Am J Pathol. 1991;138:1233-42.

75. Carloni V, Romanelli RG, Pinzani M, Laffi G, Gentilini P. Expression and function of integrin receptors for collagen and laminin in cultured human hepatic stellate cells. Gastroenterology. 1996;110:1127-36.

76. Racine-Samson L, Rockey DC, Bissell DM. The role of alphalbeta1 integrin in wound contraction. A quantitative analysis of liver myofibroblasts in vivo and in primary culture. J Biol Chem. 1997;272:30911-7.

77. Bataller R, Nicolás JM, Ginees P, Gorbig MN, García-Ramallo E, Lario S, et al. Contraction of human hepatic stellate cells activated in culture: a role for voltage-operated calcium channels. J Hepatol. 1998;29:398-408.

78. Bataller R, Gasull X, Ginés P, Hellemans K, Gorbig MN, Nicolas JM, et al. In vitro and in vivo activation of rat hepatic stellate cells results in de novo expression of L-type voltageoperated calcium channels. Hepatology. 2001;33:956-62.

79. Yanagisawa M, Kurihara S, Kumura Y, Tomobe Y, Kobayashi M, Mitsui Y, et al. A novel potent vasoconstrictor peptide produced by vascular endothelial cells. Nature. 1988;332:411-5.

80. Masaki T, Yanagisawa M, Goto K. Physiology and pharmacology of endothelins. Med Res Rev. 1992;12:391-421.

81. Gandhi CR, Behal RH, Harvey SA, Nouchi TA, Olson MS. Hepatic effects of endothelin. Receptor characterization and endothelin-induced signal transduction in hepatocytes. Biochem J. 1992;287:897-904.

82. Housset C, Rockey DC, Bissell DM. Endothelin receptors in rat liver: lipocytes as a contractile target for endothelin 1 . Proc Natl Acad Sci U S A. 1993;90:9266-70.

83. Tran-Thi TA, Kawada N, Decker K. Regulation of endothelin-1 action on the perfused rat liver. FEBS Lett. 1993;318: 353-7.

84. Rockey DC, Weisiger RA. Endothelin induced contractility of stellate cells from normal and cirrhotic rat liver: implications for regulation of portal pressure and resistance. Hepatology. 1996;24:233-40.

85. Reichen J, Gerbes AL, Steiner MJ, Sagesser H, Clozel M. The effect of endothelin and its antagonist Bosentan on hemodynamics and microvascular exchange in cirrhotic rat liver. J Hepatol. 1998;28:1020-30.

86. Morcillo E, Cortijo J. Mediadores celulares III. Angiotensinas, cininas, citocinas y otros mediadores peptídicos. En: Flórez J, Armijo JA, Mediavilla A. Farmacología humana. 3. ${ }^{\text {a }}$ ed. Barcelona: Editorial Masson S.A.; 1997. p. 343-53.

87. Wei H, Lu H, Li D, Zhan Y, Wang Z, Huang X. The expression of AT1 receptor on hepatic stellate cells in rat fibrosis induced by CCl4. Chin Med J (Engl). 2001;114:583-7.

88. Bataller R, Ginés P, Nicolás JM, Gorbig MN, García-Ramallo $\mathrm{E}$, Gasull X, et al. Angiotensin II induces contraction and proliferation of human hepatic stellate cells. Gastroenterology. 2000;118:1149-56.

89. Zhang Y, Yang X, Wu P, Xu L, Liao G, Yang G. Expression of angiotensin II type 1 receptor in rat hepatic stellate cells and its effects on cell growth and collagen production. Horm Res. 2003;60:105-10.

90. Yoshiji H, Kuriyama S, Yoshii J, Ikenaka Y, Noguchi R, Nakatani T, et al. Angiotensin-II type 1 receptor interaction is a major regulator for liver fibrosis development in rats. Hepatology. 2001;34:745-50.

91. Kurikawa N, Suga M, Kuroda S, Yamada K, Ishikawa H. An angiotensin II type 1 receptor antagonist, olmesartan medoxomil, improves experimental liver fibrosis by suppression of proliferation and collagen synthesis in activated hepatic stellate cells. Br J Pharmacol. 2003;139:1085-94. 
92. Bataller R, Sancho-Bru P, Ginés P, Lora JM, Al-Garawi A, Sole M, et al. Activated human hepatic stellate cells express the renin-angiotensin system and synthesize angiotensin II. Gastroenterology. 2003;125:117-25.

93. Baik SK, Jo HS, Suk KT, Kim JM, Lee BJ, Choi YJ, et al. Inhibitory effect of angiotensin II receptor antagonist on the contraction and growth of hepatic stellate cells. Korean J Gastroenterol. 2003;42:134-41.

94. Bataller R, Nicolás JM, Ginés P, Esteve A, Nieves Gorbig M, García-Ramallo E, et al. Arginine vasopressin induces contraction and stimulates growth of cultured human hepatic stellate cells. Gastroenterology. 1997;113:615-24.

95. Islam MZ, Williams BC, Madhavan KK, Hayes PC, Hadoke PW. Selective alteration of agonist-mediated contraction in hepatic arteries isolated from patients with cirrhosis. Gastroenterology. 2000;118:765-71.

96. Decker K. The response of liver macrophages to inflammatory stimulation. Keio J Med. 1998;47:1-9.

97. Bredt DS, Snyder SH. Nitric oxide a physiologic messenger molecule. Annu Rev Biochem. 1994;63:175-95.

98. Marletta MA. Nitric oxide synthase structure and mechanism. J Biol Chem. 1993;268:12231-4

99. Li H, Forstermann U. Nitric oxide in the pathogenesis of vascular disease. J Pathol. 2000;190:244-54.

100. Lowenstein CJ, Dinerman JL, Snyder SH. Nitric oxide a physiologic messenger. Ann Intern Med. 1994;120:227-37.
101. Mittal MK, Gupta TK, Lee FY, Sieber CC, Groszmann RJ. Nitric oxide modulates hepatic vascular tone in normal rat liver. Am J Physiol. 1994;267:G416-G22.

102. Gupta TK, Toruner M, Chung MK, Groszmann RJ. Endothelial dysfunction and decreased production of nitric oxide in the intrahepatic microcirculation of cirrhotic rats. Hepatology. 1998;28:926-31.

103. Albanis EL, Safadi RL, Friedman SL. Treatment of hepatic fibrosis. Almost there. Curr Gastroenterol Rep. 2003;5:4856.

104. Friedman SL. Liver fibrosis-from bench to bedside. J Hepatol. 2003;38:38-53.

105. Waring P, Beaver J. Gliotoxin and related epipolythiodioxopiperazines. Gen Pharmacol. 1996;27:1311-6.

106. Peralta O, Lagunas A, Madrid V. Transforming growth factor beta-1: structure, function, and regulation mechanisms in cancer. Salud Publica Mex. 2001;43:340-51.

107. Prud'homme GJ, Piccirillo CA. The inhibitory effects of transforming growth factor-beta-1 (TGF-beta1) in autoimmune diseases. J Autoimmun. 2000;14:23-42.

108. Everett L, Galli A, Crabb D. The role of hepatic peroxisome proliferator-activated receptors (PPARs) in health and disease. Liver. 2000;20:191-9.

109. Beljaars L, Meijer D, Poelstra K. Targeting hepatic stellate cells for cell-specific treatment of liver fibrosis. Front Biosci. 2002;7:e214-e22. 